\title{
Information on Covid-19 and Effortful Control Level: Increasing or Decreasing Anxiety?
}

\author{
Evi Afifah Hurriyati ${ }^{1,2, *}$, Sabilla Afriza ${ }^{2}$, Efi Fitriana ${ }^{1}$, Surya Cahyadi ${ }^{1}$ and Wilis Srisayekti ${ }^{1}$ \\ ${ }^{1}$ Universitas Padjadjaran, Jawa Barat 45363, Indonesia \\ ${ }^{2}$ Bina Nusantara University, Jakarta Barat 11530, Indonesia
}

\begin{abstract}
Anxiety has increased with more information about the COVID-19 outbreak. The COVID-19 information can make people more aware and care about this pandemic. However, it also can make people feel panic and anxious. Emotional induction in the information is referring to how the emotion carried by the information can affect early adult's anxiety, but the differences in effortful control level that each person has also define the level of anxiety someone experiences. The anxiety level related to effortful control is one dimension of temperament. This study is conducted in concern of the effect of emotional induction in COVID-19 information towards anxiety in high and low effortful control groups. This study used a quantitative method with quasi-experimental research. This study involves 218 early adults in an age range of 20-40 years old. This study used pictures from content information about COVID-19, Self-Assessment Manikin (SAM), Beck Anxiety Inventory (BAl), and Effortful Control Questionnaire (ECQ) as the measuring tools. The results of the significance test show $p<0.005$. This means that there is an effect of emotional induction on anxiety at both high and low effortful control levels. This study shows that emotional induction in the form of COVID-19 information reduces anxiety in the respondent group with a high level of effortful control, but increases anxiety in the respondent group with a low level of effortful control. The effect of COVID-19 information on anxiety based on effortful control in the late adult (over 65 years old) group, in this study cannot be explained.
\end{abstract}

Keywords: Anxiety, emotional induction, effortful control, OVID-19.

\section{INTRODUCTION}

Amid the sudden COVID-19 virus outbreak, the world seems to be shaken with and anxiety. Everyone panics and feels anxious with more information and appeals regarding the virus outbreak. In several countries, a lockdown is imposed where cities and even a whole country prohibit activities outside of home, traveling, or being visited for some time. However, in Indonesia there is no lockdown but, based on various considerations, PSBB (Pembatasan Sosial Berskala Besar) or Large-Scale Social Restrictions is enforced. PSBB is a government strategy to prevent the increase of COVID-19 cases by encouraging people to keep their physical distance from each other.

Along with the rapid spread of the COVID-19 pandemic, all media, including television, radio, print, and digital, continue to raise this phenomenon with various purposes such as discussing more the virus, increasing awareness of its dangers, educating the public about how to prevent it, and so on. All of these have one positive objective, which is to keep the public more aware and ensure that people are educated about the virus. One very important piece of information constantly updated is the number of cases suspected of having contracted the virus, those who

\footnotetext{
*Address correspondence to this author at the Bina Nusantara University, Fax Jakarta 11530, Indonesia; Tel: (+62-21) 532 7630; Fax: (+62-21) 533 2985; E-mail: e_afifah@binus.ac.id
}

are positive, and those who have recovered. This point of information is constantly updated to inform as well as increase public awareness.

However, is the goal of raising awareness only raise awareness? Apart from vigilance, anxiety also increases along with the amount of information about the COVID-19 virus. This is because the information in the media can induce the emotions of people who see or are exposed to this information constantly.

Emotional induction is a stimulus that is given to stimulate hormonal and autonomic responses that prepare the body for a variety of complex reactions and behaviour (Ribeiro, Santos, Albuquerque, \& OliveiraSilva, 2019). Research conducted in China shows that the average rate of anxiety, depression, and the combination of depression and anxiety increased rapidly compared to a study conducted in 2013 . These results also conclude that $82 \%$ of the studied respondents were those who actively use social media regularly and continuously (Montano \& Acebes, 2020). Quoted from Beck (1992), media representation plays a very important role in characterizing danger, which then creates a potential hazard.

In the case of the COVID-19 virus outbreak, which is within the scope of science, Allan, Adam, and Carter (2000) state that society is very dependent on media because the dangers and risks are not easily understood by simple logic and everyday experience (Guo, Li, \& Chen, 2020). With a lot of information 
constantly broadcasted in media, people will still be exposed to and affected by COVID-19 information without having to actively search.

The anxiety that also increases along with information about the COVID-19 pandemic is a positive impact as well as a negative impact. It is said to be positive because it can make the public more alert and concerned about this outbreak, but also negative because of the community panics and feels anxious, even though there are lots of appeals and strategies to prevent the transmission of COVID-19 that must be followed so they are protected from the virus.

This is consistent with Garofalo (1981, p. 814) who states that anxiety is an indication of panic (Baumgaertner, Colvin, \& Birch, 2018). Quoted from DSM-V by American Psychiatric Association (2013), anxiety is a disorder that shows feelings of fear and anxiety, where fear here means an emotional response to disturbances or threats in real life, while anxiety is the anticipation of threats in the future (Razzaghi, 2014). Anxiety is not always within the immediate area of a clinical disorder that requires professional help because of anxiety has a spectrum of severity. State anxiety is a form of anxiety that reflects psychological and physiological reactions at a specific time, while trait anxiety is a form of anxiety related to a person's personality and is more stable for a long time (Leal, Goes, da Silva, \& Teixeira-Silva, 2017). In this phenomenon, the anxiety in question is state anxiety, not trait anxiety related to a person's personality, because the anxiety being observed is what appears during a pandemic.

With the amount of information constantly provided, people who are continuously exposed can experience anxiety, but to varying degrees. These different levels are factored by an ability that each person has, their effortful control. This ability is one dimension of temperament, which also affects anxiety. Quoted from Diamond (1957), the structure of temperament consists of anxiety and general fear, along with impulsivity, affiliation, and aggressiveness (Strelau \& Zawadzki, 2011). Effortful control itself, according to Kochanska et al. (2004), is defined as a process of attention regulation that occurs intentionally, obstructs inappropriate behaviour, and behaves adaptively. An aspect that can also play a role in anxiety is effortful control. Effortful control is one aspect that can affect the level of anxiety of a person and is part of their temperament. By definition, according to Rothbart and Rueda (2005), effortful control is the ability to move and focus attention, and bring up dominant behaviour or sub-dominant responses (Vijayakumar et al., 2014). Effortful control can keep a person from anxiety, since it involves the process of voluntary attention regulation, restraining inappropriate behaviour, and behaving with an adaptive attitude ( $\mathrm{Li}$, Chen, $\mathrm{Li}, \& \mathrm{Li}, 2014$ ). Therefore, when one's effortful control ability is good, then the person can divert their attention from the things that make them anxious. Then, the anxiety they experience is relatively lower. This is consistent with Moriya and Tanno (2008) who stated that effortful control has a negative effect on anxiety, which means that if a person's effortful control is high or has increased, the anxiety they experience is relatively low or decreases (Kanske \& Kotz, 2012).

Attention can be the key to a person's anxiety. People with anxiety tend to process threatening and negative information first, which in turn can exacerbate the anxiety experienced (Yiend et al., 2015). With negative and threatening information continuously provided through the media, it will be increasingly difficult for people to move their attention away from it, so the anxiety they experience will increase. Quoted from McNaughton-Cassill (2001), a study shows that people who were shown information with negative material showed an increase in anxiety and sad mood after seeing the information, compared to those who were shown positive or neutral information (Johnston \& Davey, 1997).

Further, research in India related to the impact of the COVID-19 pandemic shows that $72 \%$ of all 662 participants admitted to feeling anxious about their health and those closest to them, and $40 \%$ of participants admitted to feeling paranoid or afraid of the thought of being infected by COVID-19 since the pandemic has worsened in recent weeks (Roy et al., 2020). In Indonesia, 24 out of 30 respondents in Jakarta with an average age range of 22-25 years admitted that they have experienced anxiety since the COVID-19 pandemic started. $80 \%$ of the respondents stated that they feel more anxious after seeing information related to statistical data on the number of ODP (Person Under Supervision) and victims who died. Also, the respondents also stated that they become more anxious when they have to leave the house and become more concerned about their health and cleanliness.

These results show that information about COVID19 with its negative emotional content induces 
emotions in viewers, which leads to an increase in anxiety. If this continues without treatment, there is a concern that not only physical health is threatened because of the COVID-19 virus, but also the mental health of people who are continuously exposed to COVID-19 information. Besides, in September 2020, the World Health Organization (WHO) issued a ban on visits to and from Indonesia due to the increasing number of COVID-19 cases. According to Syaifullah Tamliha, quoted from the Jakarta Post on September 10,2020 , the fact that Indonesia is a country with a travel ban should be a reminder that Indonesia is currently in a very precarious condition. However, if we look at the new normal condition as it is today, there are more and more people leaving the house when they are told to stay at home. This is also a concern because amid an increasingly emergency outbreak, many people do not care even though information through the media is continuously given.

From the explanation above, it can be seen that the community is in a condition that is very prone to experiencing anxiety and a condition where people are not at all anxious. Therefore, they do not care about the appeal to avoid leaving the house. Seeing this phenomenon, the researcher is interested in examining the role of emotional induction of COVID-19 information on respondents' anxiety with high and low effortful control abilities. Does the continuous exposure to information affect respondents' anxiety and how does the emotional induction affect the anxiety of respondents who have high and low levels of effortful control? This study involved respondents with an early adult age range (20-40 years).

\section{METHODS}

\section{Participant}

Populationinvolved in this research has the following characteristics: male and female; aged 20-40 years or in early adulthood, have access to media and the internet; and are not suspect of COVID-19. This study was conducted in Indonesia, from April until July 2020

\section{MATERIAL AND PROCEDURE}

\section{Anxiety Questionnaire}

To measure this variable, the measuring instrument used is the Beck Anxiety Inventory (BAl). The range of scores for this measure is 63 . A total score of $0-7$ is interpreted as low anxiety, a total score of $8-15$ is interpreted as mild anxiety, a total score of $16-25$ is interpreted as moderate anxiety, and a total score of 26-63 is interpreted as severe anxiety (Halfaker, $\mathrm{Ba}$, \& Practice, 2011). To test the validity and reliability of this measuring instrument, the researchers tested the validity and reliability. The results of the two tests are item number 1 must be discarded because it is not reliable, with test results showing the number 0.28 . Apart from item number 1, all items are proven to be reliable and valid with the Cronbach Alpha number on the reliability test was 0.91 and none of the validity tests was smaller than 0.30 . This measuring instrument has a total of 21 items used to measure anxiety. To measure it, respondents were asked to fill in each item on a Likert scale from 0-3, where 0 means "not at all", 1 means "a little - but not too annoying", 2 means "moderate - sometimes makes me feel uncomfortable", and 3 means "Badly - it bothers me a lot"

\section{Emotional Induction}

The measuring tool used to measure this variable is the Self-Assessment Manikin (SAM), which is developed from the Semantic Differential Scale (SDS). This measuring tool provides 3 series of pictures that represent 3 dimensions of emotion. Each series consists of 5 pictures. In the first series of pictures, to measure the dimension of pleasure, the range of pictures shows a figure with a smiling face means positive. Itchangesuntil the point is neutral, and progressively to the right showing a frowning face which means negative. The second series of pictures measure the arousal dimension, the left-most figure with the biggest "explosion" shows high intensity, it continues to decrease until the far-right figure shows a low intensity. Finally, a series of pictures measuring the dimension of dominance shows a small figure on the far left which shows subtlety, the bigger the figure to the right, the more dominant it is. Each dimension has a different scale even though the scales are both 1-9.

\section{Effortful Control Questionnaire}

This aspect is one of the dimensions of temperament so the measuring instrument used to measure this aspect is adapted from the Adult Temperament Questionnaire (ATQ). This item has 19 items with a Likert scale from 1-7 so the total scale is 133. Therefore, if the respondent's data is below 66.5 , the effortful control can be said as low, while the respondent's data is above 66.5, the effortful control 
can be said as high. The last measuring instrument used to measure this variable is the Effortful Control Questionnaire. Before being used, this measuring instrument was first tested for validity and reliability. From a total of 19 items, there were no items that needed to be thrown away or could not be used. All items on this measuring instrument are valid and reliable by showing a reliability figure of 0.70 .

\section{RESEARCH DESIGN}

This research is included in quasi-experimental research. Quasi-experiments are research methods that are carried out when random assignments are not possible.. In this study, we want to know the role of emotional induction of information about COVID-19 on anxiety which has different levels of effortful control, high and low. Therefore, emotional induction is given at the beginning of the questionnaire by providing attachments related to COVID-19.

The sampling technique in this study involves 218 respondents, who were divided into 2 groups, namely the experimental group and the control group, who were selected using a convenience sampling technique. The research was conducted by the researcher online. Questionnaires that had been formulated and transformed into Google Forms were distributed through personal social media such as Instagram and Twitter. The researcher also distributed research questionnaires via messenger applications such as Whatsapp. The researcher chose social media as a medium for distributing questionnaires because it was practical, did not require money, and it was easy to reach respondents with predetermined criteria.

Before carrying out the research, the researcher first conducted a try-out by distributing a questionnaire with text attachments of information about COVID-19 such as information on the number of COVID-19 cases and information on PSBB.Also, the attachments provided were also pictures such as posters of the symptoms of COVID-19, how to prevent contracting the virus, and pictures of medics on duty taken online news. The steps taken during the try out were repeated when distributing the questionnaire to the field without changing steps. The procedure is as follows: all participants filled out their identity data and demographic data before filling out the questionnaire and filling out the informed consent.

For the experimental group, participants were given 6 different pictures of information about COVID 19. Then they were asked to fill in the manipulation check sheet, i.e. Self-Assessment Manikin (SAM), which was also used previously to see which type of content was more inducing. This SAM gauge was provided at the end of each information or poster regarding COVID-19. The researcher attached 6 pieces of information, so the SAM was repeated 6 times.

The experimental group after filling in the SelfAssessment Manikin (SAM) then filled out the Beck Anxiety Inventory (BAI) to measure the level of anxiety. The last measuring tool used is the Effortful Control Questionnaire to measure the level of effortful control. The control group did the same thing as the experimental group, except they were not given emotional induction in the form of COVID-19 information and did not fill in the SAM manipulation check.

The collected data were then analysed using statistical tools. Data processing is done by the author first to map the level of effortful control of respondents and classify them based on their level, high or low. After being divided into 2 groups, the new authors calculated the data obtained separately by the group to see how the anxiety level of a person with low or high effortful control.

\section{Analytical Statistic}

This study uses Kruskall Wallis as a data processing method. The function of this test is to see the average effect of emotional induction and effortful control on anxiety. Then, the results of these calculations can show a comparison of the average anxiety of each group of variables. In this study, the researcher wanted to see whether there is an effect of emotional induction on respondents' anxiety which was grouped into a control and experimental group with each group is based on the level of effortful control.

\section{RESULT AND DISCUSSION}

\section{Overview of Participants}

The number of study participants was 218 , consisting of $103(47.2 \%)$ participants in the high effortful control group and $115(52.8 \%)$ participants in the low effortful control group. The participants were between 20-40 years old (Mean 20.91, Standard of Deviation. 1.61). Participant's demographic data can be seen in Table 1 below.

Table 1 shows that the largest number of participants were women $(76.1 \%)$, we're still students $(83.5 \%)$ and unmarried (93.6\%). 
Table 1: Demographic Data

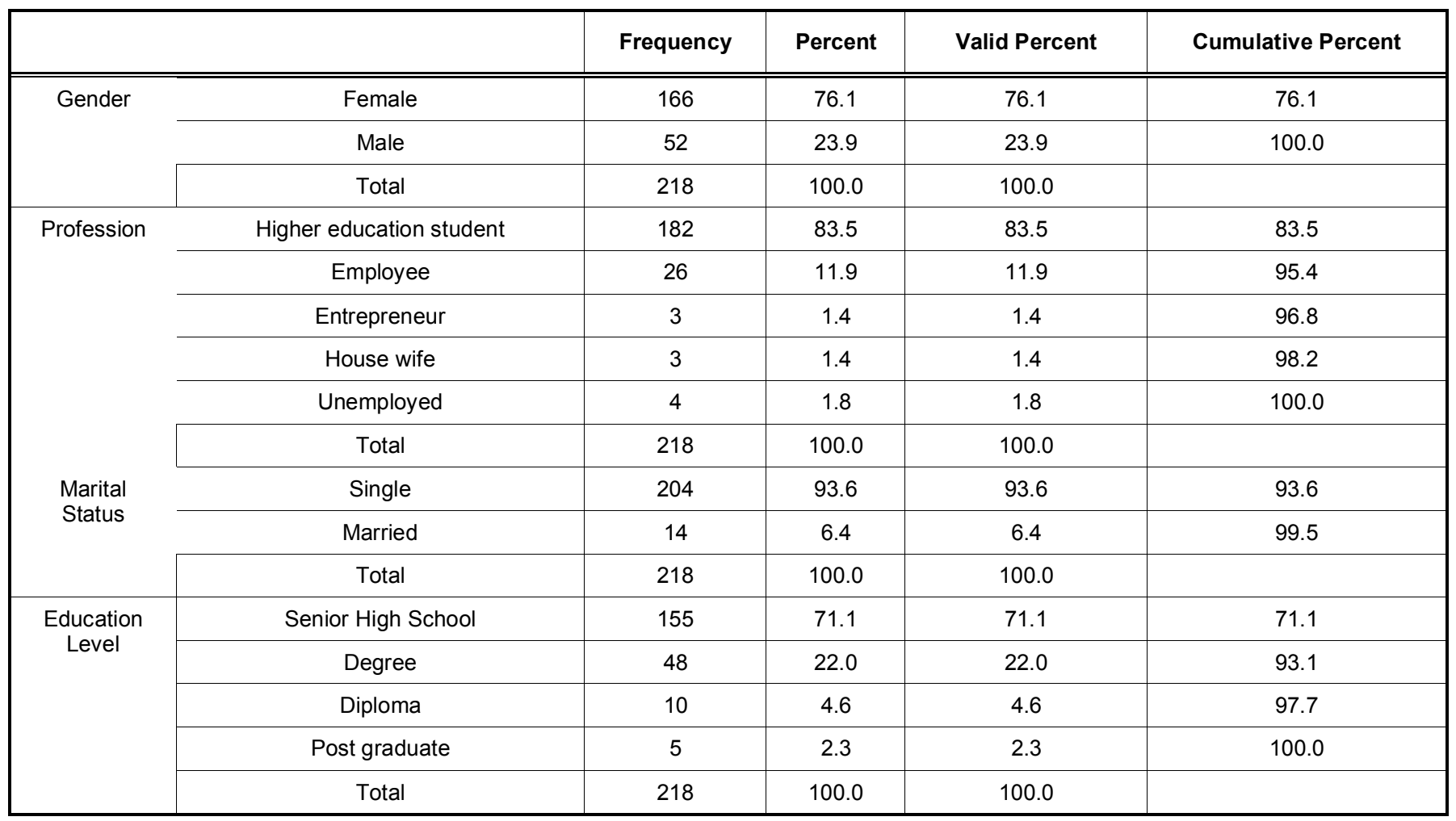

Table 2: Distribution of Participants by Domicile

\begin{tabular}{|c|c|c|c|c|}
\hline Regions & Frequency & Percentage & Valid Percentage & Cumulative Percentage \\
\hline Banten & 28 & 12.8 & 12.8 & 12.8 \\
\hline Jakarta & 39 & 17.9 & 17.9 & 30.7 \\
\hline West Java & 56 & 25.7 & 25.7 & 56.4 \\
\hline East Java & 26 & 11.9 & 11.9 & 68.3 \\
\hline Central Java & 13 & 6.0 & 6.0 & 74.3 \\
\hline West Sumatera & 2 & .9 & .9 & 75.2 \\
\hline South Sumatera & 5 & 2.3 & 2.3 & 77.5 \\
\hline West Kalimantan & 2 & .9 & .9 & 78.4 \\
\hline South Kalimantan & 4 & 1.8 & 1.8 & 80.3 \\
\hline Central Kalimantan & 1 & .5 & .5 & 80.7 \\
\hline East Kalimantan & 5 & 2.3 & 2.3 & 83.0 \\
\hline Lampung & 3 & 1.4 & 1.4 & 84.4 \\
\hline Riau & 7 & 3.2 & 3.2 & 87.6 \\
\hline Yogyakarta & 13 & 6.0 & 6.0 & 93.6 \\
\hline North Sulawesi & 3 & 1.4 & 1.4 & 95.0 \\
\hline South Sulawesi & 3 & 1.4 & 1.4 & 96.3 \\
\hline Bali & 4 & 1.8 & 1.8 & 98.2 \\
\hline Jambi & 2 & .9 & .9 & 99.1 \\
\hline Outside Indonesia & 2 & .9 & .9 & 100.0 \\
\hline Total & 218 & 100.0 & 100.0 & \\
\hline
\end{tabular}


Table 2 shows the distribution of participants based on their domicile. Based on Table 2, it can be seen that the largest number of participants are in West Java, Jakarta, Banten, and East Java, which happen to be among the areas with the highest levels of COVID-19 infection in Indonesia.

\section{Data Analysis}

After being tested by the Kolmogorov-Smirnov normality test, the collected data were not normally distributed. The data are also not homogeneous. Therefore, the Kruskall Wallis test was carried out to see the comparison of the average anxiety of each group. In this study, the average is seen from 2 things, based on the treatment and based on the level of effortful control.

Table 3: Significance Test of Emotion Induction Effect on Anxiety

\begin{tabular}{|c|c|}
\hline & Anxiety \\
\hline \hline Chi-Square & 83.962 \\
\hline Df & 3 \\
\hline Asymp. Sig. & .000 \\
\hline
\end{tabular}

The results of the manipulation check measurement using SAM obtained data that, in general, the participants were induced by being exposed to images containing information about COVID-19.

The principle of the Kruskall Wallis test is that if the significance is less than 0.05 , then $\mathrm{HO}$ is rejected. The table above shows a significance of .000 , less than 0.05 , so there is an influence between emotional induction on anxiety. This means that induction in the form of information about COVID-19 can affect anxiety. Furthermore, to see if there is a group influence based on the level of effortful control, a further test is carried out.

Table 4 shows the average high and low level of effortful control values based on their dimensions in the Experiment and Control groups. Table 5 shows the results of the significance test to determine whether there is a difference between the experimental and control groups in the high and low effortful control groups.

The results of the significance test show that $p$ $<0.005$. This means that there is an effect of emotional induction on anxiety at both high and low effortful control levels.
Table 4: Mean of Experiment and Control Group based on Level Effortful Control

\begin{tabular}{|c|c|c|c|}
\hline \multirow{2}{*}{ Variable } & Dimension & Experiment & Control \\
\cline { 3 - 4 } & & Group & Group \\
\hline \hline \multirow{3}{*}{$\begin{array}{c}\text { Effortful } \\
\text { Control }\end{array}$} & Activation & 4.95 & 4.45 \\
\cline { 2 - 4 } & Attention & 3.02 & 2.83 \\
\cline { 2 - 4 } & Inhibitory Control & 4.71 & 4.76 \\
\cline { 2 - 4 } & Activation & 4.25 & 4.37 \\
\hline \multirow{2}{*}{$\begin{array}{c}\text { Effortful } \\
\text { Control }\end{array}$} & Attention & 2.52 & 2.81 \\
\cline { 2 - 4 } & Inhibitory Control & 4.33 & 4.96 \\
\hline
\end{tabular}

Table 5: Significance Test of Anxiety Differences by Effortful Group Control

\begin{tabular}{|c|c|c|}
\hline & Anxiety_EC_High & Anxiety_EC_Low \\
\hline \hline Chi-Square & 48.187 & 14.053 \\
\hline Df & 1 & 1 \\
\hline Asymp. Sig. & .000 & .000 \\
\hline
\end{tabular}

The table above is a table of the mean for each dimension of the anxiety variable in the high and low effortful control groups. In general, in the high effortful control group, the experimental group had a lower level of anxiety than the control group. This means that the COVID-19 information as emotional induction reduces anxiety levels in the high effortful control group. Table 6 shows that the emotional induction of COVID-19 information increases the level of anxiety in the low effortful control group. This can be seen from the higher anxiety score in the experimental group than in the control group.

Table 6: Table of Differences in Anxiety Levels between the Experiment and Control Groups in the High and Low Effortful Control Groups

\begin{tabular}{|c|c|c|c|}
\hline \multirow{2}{*}{ Variable } & Dimension & $\begin{array}{c}\text { Experiment } \\
\text { Group }\end{array}$ & $\begin{array}{c}\text { Control } \\
\text { Group }\end{array}$ \\
\hline \hline \multirow{3}{*}{$\begin{array}{c}\text { High Effortful } \\
\text { Control Anxiety }\end{array}$} & Neurophysiological & 1.12 & 2.11 \\
\cline { 2 - 4 } & Autonomy & 1.13 & 1.78 \\
\cline { 2 - 4 } & Panic & 1.59 & 0.63 \\
\hline \multirow{2}{*}{$\begin{array}{c}\text { Low Effortful } \\
\text { Control Anxiety }\end{array}$} & Subjective & 1.5 & 0.71 \\
\cline { 2 - 4 } & Neurophysiological & 1.32 & 0.72 \\
\cline { 2 - 4 } & Autonomy & 1.36 & 0.66 \\
\cline { 2 - 4 } & Panic & 1.59 & 0.63 \\
\hline
\end{tabular}

During a pandemic, it is quite difficult to find respondents with older adults (over 65 years). They are 
not used to filling out online questionnaires with a large number of items. We only got 5 respondents in the experimental group. Therefore these data were not included in the data analysis. However, descriptively the level of anxiety (mean 164.20, standard deviation 33.19) and effortful control (79.80, standard deviation 21.81) of the five respondents can be reported. The results showed that $40 \%$ of elderly respondents had a high level of anxiety, $60 \%$ had a low level of anxiety. The research also shows that $60 \%$ of respondents have a high level of effortful control and $40 \%$ have a low level of effortful control. However, the effect of COVID-19 information on anxiety based on effortful control in the late adult group, in this study cannot be explained.

\section{DISCUSSION}

Information on COVID-19 as an emotional induction in this study affects individual anxiety levels. Anxiety is a form of the negative effect that can be experienced by everyone. The level of anxiety in this study is also influenced by the level of effortful control. Based on the research data, it shows that the control group with high effortful control has a relatively higher level of anxiety than the experimental group.

Participants in this group were categorized as having moderate anxiety levels. Rothbart and Sheese (2007) state that a person with a high level of behavioural inhibition or effortful control has a high and active fear system which ultimately limits the person's behaviour and attention. When someone has high effortful control, then that person can experience an excessive level of control, so the person becomes inflexible (Block \& Block, 1980; Carver, 2005). Excessive control and rigidity are what increase a person's anxiety (White, McDermott, Degnan, Henderson, \& Fox, 2011). However, after being induced with information containing negative emotional content, anxiety levels decreased. This can be seen in the experimental group with high effortful control which is categorized as having a somewhat anxious level of anxiety. This is because providing information provides a little certainty for respondents, given that anxiety is a condition in which individuals feel afraid and worried about uncertain things, so when given the information the respondent feels more certain about COVID-19.

Feeling certain on information about COVID-19 can cause anxiety in participants with a high level of effortful control. This is also shown in research conducted by Bolejko and Hagell (2020) on a group of patients who undergo an MRI test. This study was conducted to see whether providing information about the MRI test in advance would help patients feel calmer and less anxious about the test. Information is provided in the form of a booklet which contains a list of information about MRI, such as an MRI test, what are the steps, what happens if you do not have an MRI test, and other basic things. The results of this study indicate that patients who received the information in advance showed calmer behavior, were less anxious and afraid, even more, cooperative during the MRI test because they already knew the MRI test.

Another important factor in how a person can experience low anxiety despite being stimulated is his attention. Someone with a good ability to move and focus their attention can help reduce negative emotions and effects, so they are more immune to internalizing problems (Elsenberg, Hofer, Sulik, \&Spinrad, 2014). The ability to move and focus good attention can help individuals reduce negative effects such as anxiety.

Other studies show different results, research conducted by de HoogandVerboon (2020) states that continuous exposure to negative information is associated with negative effects compared to positive effects. The researcher suspects that the study participants are individuals with a low level of effortful control.

In contrast to individuals with a high level of effortful control, according to research conducted by Gulley, Hankin, and Young (2016), it does not show a relationship between negative effects and symptom internalization in people with a relatively low level of effortful control. This is because people with a low level of effortful control have very few effective coping strategies to regulate adversity so it makes no difference under any stressful conditions, whether under stressful or low levels. Likewise in this study, participants with a low level of effortful control had relatively lower levels of anxiety than the experimental group. The experimental group with a low level of effortful control showed a higher or increased level of anxiety than the control group. This can indicate that participants with low effortful control when exposed to information about COVID-19 their levels of anxiety increased. This is because they have little coping strategies so they are unable to regulate their anxiety.

The results of this study imply that it can explain a little about people's behaviour when facing COVID-19 pandemic. Anxiety is the result of people's emotions 
that have to adapt and find ways to survive. The definition of emotion according to Lerner, Li, Valdesolo, and Kassam (2015) is various biologically mediated reactions (based on experience, that appear along with events related and relevant to self-defense. Especially for people who are in the age range of 20-40 years or are in the young adult phase, cognitively, young adults are more mature both for their logical abilities and their ability to think abstractly. They can easily understand health protocols, so if they follow health protocols then they believe that they will be safe. Also, they are required to leave the house because many offices have started operating normally again, and several universities have started rescheduling face-to-face lectures so that they inevitably have to leave the house. Following the statement put forward by Taylor (2019) above, a person's anxiety will subside because they do not experience the consequences of what they are anxious about.

Information about COVID-19 that was conveyed by the government as a policymaker must still be socialized and needed with the pandemic has not ended. Proportional information about COVID-19 can reduce anxiety in individuals who have a high level of effortful control, so they can carry out health protocols as an effort to overcome their anxiety. Meanwhile, for individuals with a low level of effortful control, information about COVID-19 can increase their anxiety, so they are expected to be more alert and not neglect health protocols.

\section{CONCLUSION}

This study shows that emotional induction in the form of COVID-19 information has a significant effect on the level of anxiety in the group of participants with a high level of effortful control by reducing the level of anxiety. On the contrary, the same emotional induction increases the level of anxiety in the group of participants with a low level of effortful control. The benefit of this research is to give a little picture of the mental health of the Indonesian people amid the COVID-19 pandemic based on effortful control level. Also, the current research implies that the government must maintain the intensity of information and educational programs to the whole community regarding COVID-19 to decrease the rate of COVID-19 cases.

This study has several limitations, such as conditions that allow for data bias because exposure to COVID-19 information existing in everyday life is not completely controlled when participating in the research. Besides, this study did not measure the participants' anxiety trait that could influence this study. The researcher suggests that further research can use pure experimental methods, so the internal and external validation of this study are well maintained. Future research could be conducted using within and between subjects. There is also a difference between before and after being given emotional induction. Also, further research is suggested to examine the factors that affect the level of effectiveness of information on anxiety based on age groups, education, and personality.

\section{REFERENCES}

Business and Management Review, 6(11), 40-47. https://doi.org/10.12816/0040336

Baumgaertner, R., Colvin, E., \& Birch, P. (2018). Moral Panic and Perceptions of Community Fear: A Local Community Study Examining Drug Use. Salus Journal, 21(2), 21-36.

Beck, A. T., \& Clark, D. A. (1988). Anxiety and depression: An information processing perspective. Anxiety Research, 1(1), 23-36. https://doi.org/10.1080/10615808808248218

Bradley, M., \& Lang, P. J. (1994). 5-cite3060-1994-Measuring Emotion: The Self-Assessment Semantic Differential Manikin and the. Journal of Behavior Therapy and Experimental Psychiatry, 25(I), 49-59. https://doi.org/10.1016/0005-7916(94)90063-9

Buechel, S., \& Hahn, U. (2017). Readers vs. writers vs. texts: Coping with different perspectives of text understanding in emotion annotation. LAW 2017 - 11th Linguistic Annotation Workshop, Proceedings of the Workshop, (April), 1-12. https://doi.org/10.18653/v1/W17-0801

Clark, D.A. \& Beck, A. T. (1954). Cognitive Therapy of Anxiety Disorders. The Guilford Press.

Elsenberg, N., Hover, C., Sulik, M. J., \& Spinrad, T.L. (2014). Selfregulation, effortful control, and their socioemotional correlates. Handbook of emotion regulation, 2, 157-172.

Etikan, I. (2016). Comparison of Convenience Sampling and Purposive Sampling. American Journal of Theoretical and Applied Statistics, 5(1), 1. https://doi.org/10.11648/j.ajtas.20160501.11

Faasse, K., Porsius, J. T., Faasse, J., \& Martin, L. R. (2017). Bad information: The influence of information coverage and Google searches on Gardasil adverse event reporting. Vaccine, 35(49), 6872-6878. https://doi.org/10.1016/j.vaccine.2017.10.004

Fakhrhosseini, S. M., \& Jeon, M. (2017). Chapter 10 - Affect/Emotion Induction Methods. In Emotions and Affect in Human Factors and Human-Computer Interaction. https://doi.org/10.1016/B978-0-12-801851-4/00010-0

Gribbons, B., \& Herman, J. (1997). True and Quasi-Experimental Designs True and Quasi-Experimental Designs .5(1996), 1996-1997.

Gulley, L. D., Hankin, B. L., \& Young, J. F. (2016). Risk for Depression and Anxiety in Youth: The Interaction Between Negative Affectivity, Effortful Control, and Stressors. 44(2). 207-218. https://doi.org/10.1007/s10802-015-9997-7

Guo, Y., Li, Y., \& Chen, L. (2020). After Fukushima: How Do Information Media Impact Japanese Public's Risk Perception 
and Anxiety Regarding Nuclear Radiation. Environmental Communication, 14(1),97-111.

https://doi.org/10.1080/17524032.2019.1614966

Halfaker, D. A., Ba, T. L. W., \& Practice, C. (2011). Beck Anxiety Inventory Psychological Aspects of Pain Assessment of Anxiety in Older Adults Neurobiology of Psychiatric Disorders.

Han-Kyeong Lee, Jihae Kim, SanghwangHong, Eun-ho Lee, \& Hwang Soon Taeg. (2016). Psychometric Properties of the Beck Anxiety Inventory in the Community-dwelling Sample of Korean Adults. Korean Journal of Clinical Psychology, 35(4), 822-830. https://doi.org/10.15842/kjcp.2016.35.4.010

Hill, B. V. (1973). Operational Definitions in Educational Research. Australian Journal of Education, 17(1), 25-33. https://doi.org/10.1177/000494417301700104

Hoyt, D. (2016). Optimism as a Mediating Factor in the Relationship between Anxiety and Information Media Exposure in College Students. (December).

Kahn, R. E., Chiu, P. H., Deater-Deckard, K., Hochgraf, A. K., KingCasas, B., \& Kim-Spoon, J. (2018). The Interaction Between Punishment Sensitivity and Effortful Control for Emerging Adults' Substance Use Behaviors. Substance Use and Misuse, 53(8), 1299-1310. https://doi.org/10.1080/10826084.2017.1407790

Klemm, C., Hartmann, T., \& Das, E. (2019). Fear-Mongering or FactDriven? Illuminating the Interplay of Objective Risk and Emotion-Evoking Form in the Response to Epidemic Information. Health Communication, 34(1), 74-83. https://doi.org/10.1080/10410236.2017.1384429

Leal, P. C., Goes, T. C., da Silva, L. C. F., \& Teixeira-Silva, F. (2017). Trait vs. state anxiety in different threatening situations. Trends in Psychiatry and Psychotherapy, 39(3), 147-157. https://doi.org/10.1590/2237-6089-2016-0044

Lerner, J. S., Li, Y., Valdesolo, P., \& Kassam, K. S. (2015). Emotion and Decision Making. Annual Review of Psychology, 66(1), 799-823.

https://doi.org/10.1146/annurev-psych-010213-115043

Li, M., Chen, J., Li, N., \& Li, X. (2014). A twin study of problematic internet use: Its heritability and genetic association with effortful control. Twin Research and Human Genetics, 17(4), 279-287.

https://doi.org/10.1017/thg.2014.32

Madden, A. D. (2000). A definition of information. Aslib Proceedings, 52(9), 343-349. https://doi.org/10.1108/EUM0000000007027
McNaughton-Cassill, M. E. (2001). The information media and psychological distress. Anxiety, Stress and Coping, 14(2), 193-211. https://doi.org/10.1080/10615800108248354

Ng, T. W. H., Sorensen, K. L., Zhang, Y., \& Yim, F. H. K. (2019). Anger, anxiety, depression, and negative affect: Convergent or divergent? Journal of Vocational Behavior, 110, 186-202. https://doi.org/10.1016/j.jvb.2018.11.014

Razzaghi, E. M. (2014). A warm welcome to the diagnostic and statistical manual of mental disorders, fifth edition? In Iranian Journal of Psychiatry and Behavioral Sciences (Vol. 8).

Remmers, C., \& Zander, T. (2018). Why You Don't See the Forest for the Trees When You Are Anxious: Anxiety Impairs Intuitive Decision Making. Clinical Psychological Science, 6(1), 4862 https://doi.org/10.1177/2167702617728705

Ribeiro, F. S., Santos, F. H., Albuquerque, P. B., \& Oliveira-Silva, P (2019). Emotional induction through music: Measuring cardiac and electrodermal responses of emotional states and their persistence. Frontiers in Psychology, 10(MAR), 1-13. https://doi.org/10.3389/fpsyg.2019.00451

Robinson, O. C., Demetre, J. D., \& Litman, J. A. (2017). Adult life stage and crisis as predictors of curiosity and authenticity: Testing inferences from Erikson's lifespan theory. International Journal of Behavioral Development, 41(3), 426431. https://doi.org/10.1177/0165025416645201

Roy, D., Tripathy, S., Kar, S. K., Sharma, N., Verma, S. K., \& Kaushal, V. (2020). Study of knowledge, attitude, anxiety \& perceived mental healthcare need in Indian population during COVID-19 pandemic. Asian Journal of Psychiatry, 51(April), 102083. https://doi.org/10.1016/j.ajp.2020.102083

Strelau, J., \& Zawadzki, B. (2011). Fearfulness and anxiety in research on temperament: Temperamental traits are related to anxiety disorders. Personality and Individual Differences, 50(7), 907-915 https://doi.org/10.1016/j.paid.2010.07.008

Vijayakumar, N., Whittle, S., Dennison, M., Yücel, M., Simmons, J., \& Allen, N. B. (2014). Development of temperamental effortful control mediates the relationship between maturation of the prefrontal cortex and psychopathology during adolescence: A 4-year longitudinal study. Developmental Cognitive Neuroscience, 9, 30-43. https://doi.org/10.1016/i.den.2013.12.002

Wolf, C., Joye, D., Smith, T. W., \& Y, Fu. (2016). The Sage handbook of survey methodology. Thousand Oaks, CA: SAGE Publications. https://doi.org/10.4135/9781473957893 